\title{
Um estudo sobre os aspectos da dinâmica migratória internacional entre a microrregião de Governador Valadares e os Estados Unidos, 2000-2010
}

\author{
Leonardo Gomes de Sousa* \\ Dimitri Fazito ${ }^{* *}$
}

\begin{abstract}
A microrregião de Governador Valadares (MGV) é a mais representativa no cenário da emigração internacional de brasileiros para os Estados Unidos. Entretanto, na década de 2000, ocorreram situações na origem e no destino que economicamente poderiam provocar uma diminuição ou estancamento do fluxo de migrantes. Esse artigo procura analisar a hipótese de que, mesmo num cenário aparentemente adverso, a migração continuou a ocorrer na região com força considerável durante a década de 2000. Para tanto, buscou-se compreender como foi estabelecida, na MGV, a situação da emigração para os Estados Unidos e sua aderência explicativa junto às teorias sobre migrações, bem como realizar uma verificação objetiva dos volumes e fluxos de migrantes contidos neste sistema migratório. Observou-se então que, entre 2000 e 2010, o sistema de migração estruturado pelas redes sociais pessoais e demais mecanismos de perpetuação existentes na região exerceram uma força responsável pela preservação de um fluxo considerável durante esse período.
\end{abstract}

Palavras-chave: Migração internacional. Estados Unidos. Microrregião de Governador Valadares.

\footnotetext{
* Centro de Desenvolvimento e Planejamento Regional (Cedeplar), Universidade Federal de Minas Gerais (UFMG), Belo Horizonte-MG, Brasil (leogosousa@gmail.com).

${ }^{\star \star}$ Departamento de Sociologia, Universidade Federal de Minas Gerais (UFMG), Belo Horizonte-MG, Brasil (dfazito@gmail.com).
} 


\section{Introdução}

A partir de 1980 o Brasil assumiu um perfil emigratório no que tange aos deslocamentos populacionais internacionais, passando de um país que até o momento era tradicionalmente marcado como receptor de migrantes para um que perde parcela significativa de sua força de trabalho para outros países (CARVALHO, 1996; CARVALHO et al., 2000). Os Estados Unidos são o maior receptor de emigrantes brasileiros e, nos últimos 20 anos, diversos estudos têm enfatizado, sob diferentes perspectivas, a relevância deste fenômeno (GOZA, 1994; MARGOLIS, 1994; SALES, 1999; FUSCO, 2000; FAZITO, 2005; SIQUEIRA, 2006). A microrregião de Governador Valadares (MGV), localizada no estado de Minas Gerais, é uma das regiões mais representativas no cenário da emigração brasileira para os Estados Unidos.

A emigração internacional nessa região ganhou força no final da década de 1970 devido à grande crise econômica que o Brasil atravessava depois do esgotamento do "Milagre Econômico" (SOARES, 2002). A emergência do fluxo de emigração internacional e sua posterior expansão exerceram forte impacto sobre a rotina econômica e social da região devido, num primeiro momento, ao agravamento da produtividade regional ocasionado pela perda de mão de obra e, posteriormente, ao desenvolvimento econômico "desequilibrado" causado pela entrada contínua e crescente de remessas financeiras dos emigrantes internacionais que impactaram diretamente sobre a forte variação de preços no mercado imobiliário local e outros setores da economia (SOUSA; DIAS, 2010). Uma parcela significativa da população desta região tem experiência migratória internacional ou contato direto em suas redes pessoais com migrantes internacionais (e não apenas nos EUA). Um em cada nove habitantes da MGV já vivenciou algum fato concreto relacionado à migração para os EUA (por exemplo, visitou ou residiu temporariamente naquele país) e um em cada quatro tem algum conhecido que já esteve naquele país (SOARES, 2002). Segundo Fusco e Souchaud (2010), em 2000, Minas Gerais abrigava 10,5\% da população brasileira e $21 \%$ dos retornados internacionais, sendo que Governador Valadares ocupava a liderança nacional das maiores proporções entre retornados internacionais e população total.

Os ciclos exploratórios ocorridos na região de Governador Valadares desde antes de sua fundação e a estagnação econômica contribuíram para criar o estigma do lugar como "terra de passagem" (ESPINDOLA, 2005). Por outro lado, a presença de americanos no desenvolvimento local entre as décadas de 1940 e 1970 colaborou para dinamizar a economia e serviu para criar laços iniciais entre origem e destino, num potencial sistema de migração internacional, bem como a construção de um imaginário coletivo sobre a prosperidade advinda daquelas terras (SOARES, 2002).

Com o aumento do fluxo de emigrantes da região para os EUA no início da década de 1980 e a consequente imposição de barreiras legais para a travessia, pode-se dizer que, a partir do início dos anos 1990, emergiu um sistema de migração estruturado por meio de agências de turismo e agentes intermediários (brokers). Este sistema é composto por migrantes retornados internacionais que passaram a oferecer serviços de "travessia" a 
emigrantes potenciais, emigrados que passaram a receber novos "aventureiros" nos destinos estrangeiros e diversos outros nós na rede migratória que vai se fortalecer e formar o que se convencionou como uma "indústria de migração ilegal” na MGV (MARGOLIS, 1994; FAZITO; SOARES, 2014).

A economia da MGV possui uma característica histórica de "estabilidade", ou melhor, de certa estagnação econômica que tem se mantido e impedido o desenvolvimento mais vigoroso da região, mesmo nas décadas recentes de crescimento econômico do Brasil. Nesse contexto, a população parece assimilar o projeto da migração internacional, com a consolidação das redes sociais, do mercado e da cultura migratória, como uma estratégia econômica alternativa e viável diante de um cenário desfavorável. Em suma, tanto indivíduos quanto suas famílias e a comunidade da região teriam passado a considerar e instrumentalizar as oportunidades da emigração internacional como uma estratégia de sobrevivência.

Entretanto, durante a década de 2000, ocorreram alguns eventos pontuais que poderiam ter contribuído para a redução da emigração para os EUA. Pelo lado americano, o endurecimento da fiscalização após o atentado de 11 de setembro de 2001 e o estouro da bolha imobiliária nos EUA poderiam ter exercido influência sobre o retorno dos emigrados e, talvez, contribuído para sua intensificação. Pelo lado brasileiro, as mudanças econômicas e sociais impactaram positivamente na melhoria da qualidade de vida de sua população, fazendo com que a imagem de prosperidade pudesse se fixar em terras brasileiras (enfim, em tempos de crise internacional, para muitos brasileiros no exterior, o retorno teria passado a figurar como uma alternativa atraente).

Por causa de tais transformações gerais no Brasil e nos Estados Unidos, poderíamos esperar um desestímulo à emigração internacional e a redução ou estagnação dos volumes de saída especialmente em direção à América do Norte.

A motivação inicial deste artigo tem a ver com a observação superficial e cotidiana de que, mesmo num cenário aparentemente adverso, a migração continuou a ocorrer na região com alguma força, pois, de fato, como mostram os dados do Censo 2010 e observações cotidianas diretas não sistemáticas, ${ }^{1}$ muitas pessoas continuaram empenhando seu projeto migratório para os EUA e Europa a partir da MGV. Acreditamos que a preservação mínima de fluxos de saída se deve especialmente aos fatores relacionais que articulam as comunidades locais entre origem e destino, isto é, as redes sociais, o mercado da migração internacional e a cultura migratória estabelecida historicamente por este sistema migratório Brasil-EUA. Neste trabalho, consideramos o cenário econômico, passado e presente da região, para entender como o desenvolvimento de mecanismos de perpetuação do sistema de migração internacional da MGV pode ter contribuído para a manutenção de fluxos de saída durante a década. A dinâmica migratória da década de 2000 também é analisada a partir de dados censitários e outras fontes para verificação objetiva dos volumes e fluxos

\footnotetext{
${ }_{1}^{1}$ Em 2009, atuamos como consultores da OIM (International Organization for Migration) em um projeto de pesquisa na região, onde foram realizadas diversas entrevistas com emigrantes retornados, que informaram que participantes de suas redes pessoais continuavam a migrar para os Estados Unidos ou Portugal.
} 
de migrantes contidos neste sistema migratório. Ao final, procuramos argumentar conclusivamente sobre a importância dos mecanismos relacionais de perpetuação (redes sociais) e sua articulação com os diversos fatores sociais, econômicos e demográficos regionais para a preservação do sistema de migração internacional na MGV.

\section{Por que Valadares? Particularidades que contribuíram para a formação do fenômeno emigratório para os Estados Unidos}

A microrregião de Governador Valadares $(M G V)^{2}$ é uma das oito microrregiões que compõem a mesorregião do Vale do Rio Doce. Com uma área total de $11.327,403$ km², esta microrregião é considerada uma das maiores do estado de Minas Gerais, com 415.696 habitantes em 2010, dos quais 63,4\% (263.511) residem no município que dá o nome à microrregião (IBGE, 2011). Sua localização geográfica configura-se entre rotas de acesso para grandes centros como Belo Horizonte, Vitória, Rio de Janeiro e Região Nordeste do país.

A MGV vivenciou, na década de 1980, um dos mais significativos fluxos emigratórios internacionais que já existiram no Brasil para outros países. Embora haja outros importantes fluxos migratórios de brasileiros para o exterior a partir de outras regiões, a MGV é a que apresenta maior participação relativa entre os emigrantes internacionais, principalmente para os Estados Unidos (SALES, 1999; MARTES, 2000; ASSIS, 2003; FUSCO, 2006). 0 histórico econômico extrativista e grandes crises nacionais não foram exclusividades desta região (ESPINDOLA, 2005). Entretanto, outras regiões brasileiras com contextos semelhantes não experimentaram tal fenômeno de emigração internacional, sobretudo direcionado para os Estados Unidos. Quais fatores poderiam ajudar a explicar a mobilidade populacional acentuada nesta região?

Primeiro, devemos destacar a forte presença norte-americana na primeira metade do século passado em três momentos emblemáticos no desenvolvimento da região de Governador Valadares: a dinamização do mercado da mica; a reconstrução da estrada de ferro; e a criação do Sesp - Serviço Especial de Saúde Pública na região. Tais eventos contribuíram diretamente para a cristalização de um imaginário social muito positivo sobre os Estados Unidos, condensando a ideia de riqueza e oportunidades características daquele país (ASSIS, 1999). Segundo Soares (2002, p. 95), ao longo da trajetória histórica destes eventos, a imagem dos Estados Unidos “incorporou-se à extensão do conhecimento geográfico da sociedade valadarense, tornando-se 'conhecido', facilitado e mais presente”. Assim, as relações estabelecidas entre os habitantes da região de Governador Valadares e os estadunidenses permitiram a criação de laços sociais duráveis e norteadores para a opção migratória.

\footnotetext{
${ }^{2}$ A microrregião de Governador Valadares é composta por 25 municípios: Alpercata, Campanário, Capitão Andrade, Coroaci, Divino das Laranjeiras, Engenheiro Caldas, Fernandes Tourinho, Frei Inocêncio, Galileia, Governador Valadares, Itambacuri, Itanhomi, Jampruca, Marilac, Mathias Lobato, Nacip Raydan, Nova Módica, Pescador, São Geraldo da Piedade, São Geraldo do Baixio, São José da Safira, São José do Divino, Sobrália, Tumiritinga e Virgolândia.
} 
A criação, na segunda metade do século passado, do instituto de línguas Ibeu foi também um elemento determinante no início do processo emigratório para os Estados Unidos (SIQUEIRA, 2008), possibilitando o intercâmbio de valadarenses que trouxeram notícias mais concretas da sociedade americana. Estes intercambistas, ao retornarem dos EUA, relatavam de maneira idealizada aos seus pares no Brasil sobre as inúmeras oportunidades de vida e outras maravilhas daquela terra (ASSIS, 1999; SIQUEIRA, 2008).

A região de Governador Valadares tinha experimentado até então uma migração interna significativa, recebendo e enviando população de diversas regiões do Brasil e mesmo uma leve experiência de imigração internacional com alguns estrangeiros de nacionalidades italiana, espanhola e siríaca residentes na microrregião (ESPÍNDOLA, 2005; SOUSA; DIAS, 2010). A experiência pregressa, a presença marcante dos americanos em solo valadarense e as informações concretas da vida nos EUA fornecidas pelos intercambistas criaram uma visão de que a migração internacional era um projeto possível e de relativa facilidade (ASSIS, 1999; FUSCO, 2000). É nesse cenário que, no final da década de 1960, partem os primeiros valadarenses para os EUA, jovens aventureiros de famílias de classe média alta que, diante da estagnação econômica que pairava na região, viam ameaçada a manutenção do seu status quo (ASSIS, 1999; FUSCO, 2005; SIQUEIRA, 2008).

Siqueira (2008, p. 7) aponta que esses primeiros emigrantes que se estabeleceram nos Estados Unidos davam o "apoio necessário para os que desejavam emigrar, enviavam informações estratégicas, emprestavam dinheiro para o depósito junto ao consulado americano, ${ }^{3}$ buscavam no aeroporto, ofereciam estadia ou moradia, ajudavam no primeiro emprego e compravam roupas adequadas para o clima nos EUA". Assim, passados alguns anos, um grupo significativo de valadarenses já tinha emigrado e se estabelecido nos Estados Unidos até o início dos anos 1970 (SIQUEIRA, 2008).

0 desenvolvimento dessa dinâmica migratória entre indivíduos presentes nas unidades espaciais de origem e destino engendrou uma complexa rede social que potencializou 0 deslocamento para os EUA. A constituição desta rede foi determinante para a emigração em grande escala a ser observada então na década de 1980 (ASSIS, 1999; SOARES, 2002). Diversos estudos apontam que as redes sociais da migração constituem fator preponderante na concentração de indivíduos e formação de comunidades imigrantes nos EUA, como no caso dos brasileiros (MASSEY et al., 1987; TILLY, 1990; MARGOLIS, 1994; FAZITO, 2005; SIQUEIRA, 2006).

Além disso, o envio de remessas de parte considerável da renda pessoal do emigrante para a cidade de origem, em si mesmo, constitui um fato da existência de redes sociais fundamentadas nas relações de confiança que possibilitam trocas monetárias entre pessoas na origem e destino. Mas não apenas isso, pois a circulação monetária das remessas exerce também um efeito retroativo de fortalecimento e expansão das redes sociais instituídas e implicam a formação de um “mercado da migração" ampliado, visto que as trocas entre

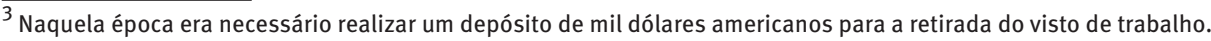


migrantes e não migrantes na origem e destino envolvem regras socialmente legitimadas para a circulação segura dos recursos econômicos e sociais (não apenas moedas, mas também bens materiais e simbólicos, como respeito, confiança e autoridade), recursos estratégicos para o planejamento e realização efetiva do projeto migratório capaz de maximizar o sucesso individual e coletivo (no âmbito das decisões tomadas no seio das famílias e comunidades locais) (GUILMOTO; SANDRON, 2001; FAZITO; SOARES, 2014).

0 grande volume de indivíduos da região que emigraram para os EUA na década de 1980 evidencia a formação e expansão de um sistema de migração internacional composto por diversos agentes e instituições que se distribuem e se organizam em um “mercado da migração". A demanda pela emigração internacional possibilitou o estabelecimento de uma "rede institucional" de agentes intermediários garantidora da travessia, muitas vezes ilegal, entre Brasil e Estados Unidos. Nota-se então o aumento significativo no número de agências de turismo que desempenhavam o papel de intermediação (brokerage) dos projetos migratórios, especialmente daqueles migrantes trabalhadores menos qualificados e incapazes de acessarem o mercado de trabalho norte-americano pelas vias regulares (FAZITO; SOARES, 2014). Segundo Soares (2002), entre 1975 e 1994, foram abertas 45 agências de turismo em Governador Valadares, das quais 27 (60\%) iniciaram suas atividades entre 1985 e 1989, considerado por vários autores o período de maior emigração valadarense para os EUA (ASSIS, 1999; SALES, 1999; FUSCO, 2000; SIQUEIRA, 2006).

O volume de emigrantes alcançado em fins da década de 1980 e início dos anos 1990 implicou, por consequência, o aumento vertiginoso nos pedidos de vistos nos consulados norte-americanos. A elevada demanda e sua novidade chamaram a atenção das autoridades estadunidenses, uma vez que o Brasil passava ainda por uma grave crise inflacionária e, paradoxalmente, entre 1984 e 1991, o número de solicitações de vistos de turista, ao invés de se retrair, aumentou em 200\% (MARGOLIS, 1994; FAZITO, 2005).

Assim, durante o fim da década de 1980 e início dos anos 1990, ocorreu, paralelamente à emigração internacional de habitantes da região, uma fase de quase fechamento de fronteiras imposta pelos Estados Unidos (SOARES, 2002). Houve um constrangimento expressivo para concessão de vistos de turismo e trabalho devido ao maior rigor das políticas de imigração americana e, principalmente, ao endurecimento dos critérios para a entrada de brasileiros (FAZITO, 2005). Até então, grande parte dos emigrantes potenciais valia-se da retirada de vistos de turista nos consulados americanos como principal estratégia para a travessia, praticando o ato irregular posterior com a permanência não autorizada a partir do término do período de vigência concedido no visto de turista (overstaying). Neste momento, diversos estudos apontam um aumento da entrada ilegal nos EUA, ou seja, sem vistos legais concedidos. A partir de então, a adoção de rotas de clandestinidade passou a fazer parte das estratégias para a maioria dos brasileiros que tentam migrar para os Estados Unidos (MARGOLIS, 1994; PATARRA; BAENINGER, 1995; SALES, 1999; SOARES, 2002; FAZITO, 2005). 
Os entraves impostos para a travessia conferem ao fluxo migratório um caráter irregular que varia de acordo com o grau de dificuldade e com investimentos que atualmente podem chegar a 25 mil reais por pessoa. As dimensões e valores variam do mais fácil ao mais complicado método de travessia, em que o primeiro consiste na obtenção de um visto de turista com o intuito real de permanecer e trabalhar nos EUA e o segundo refere-se ao ato de forjar uma documentação falsa para conseguir o visto e à dimensão mais arriscada, que é a travessia clandestina das fronteiras com os coiotes ${ }^{4}$ (SOARES, 2002).

Na década de 1990 pode-se dizer que o fenômeno da migração internacional de valadarenses consolidou-se em um sistema de migração bem estruturado, com papéis de atores e intermediários do processo muito bem delimitados. Fluxos migratórios observados em outros países de origem, como México, Índia, Tailândia e Sri Lanka, também enfatizam a importância dos mecanismos intermediários na perpetuação dos sistemas migratórios (BREMAN, 1979; EELENS; SPECKMAN, 1990; SINGHANETRA-RENARD, 1992). Fazito (2005) descreve que estes mecanismos intermediários cumprem papel decisivo na realização do trajeto espacial e social pelos migrantes. 0 autor destaca ainda que a intermediação clandestina tem seus laços com a comunidade reforçados devido ao fato de que a maioria dos agentes e administradores das agências de turismo e falsificação é composta por migrantes internacionais retornados.

As redes pessoais, formadas por familiares e amigos, e os agentes e agências existentes na região desempenham papel fundamental no sistema por agirem como impulsionadores e/ou constrangedores na decisão e execução do ato de migrar. A formalização de uma rede social migratória foi a responsável de fato pelo aumento do fluxo emigratório para os EUA, pois, a partir da criação e ampliação da rede social da migração, o sistema migratório passou tanto a organizar um “mercado da migração" quanto a reproduzir uma espécie de "cultura de migrar”, que num processo recursivo de causação cumulativa (MASSEY, 1990) determinaria a expansão e o fortalecimento das redes de migração existentes entre diferentes regiões na origem e no destino.

Margolis (1994) aponta que a cultura migratória existente na MGV foi forjada ao longo das décadas amparada pelo contato com os americanos no decorrer de seu desenvolvimento econômico, pela circulação de dólares no mercado local e, principalmente, pela constituição de uma rede social migratória ampliada que conectou atores na origem e no destino. Soares (2002, p. 96) observa que a disseminação dessa cultura de migrar é a responsável por maturar em crianças e jovens o desejo de "migrar para o exterior como parte de sua experiência de vida". Em resumo, o mercado da migração e as representações sociais acerca do processo emigratório internacional oferecem ao potencial migrante da MGV uma alternativa mais atraente com relação ao deslocamento para outro país, e menos intensa em relação à migração interna para outras regiões brasileiras.

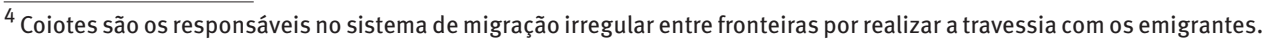


Contudo, na década de 2000, ocorreram oscilações das demandas e disposições norte-americanas com relação à fiscalização migratória, devido tanto às crises de segurança interna daquele país quanto à crise imobiliária a partir de 2006. Além disso, na outra ponta, o Brasil passou por grandes mudanças econômicas e sociais que impactaram positivamente na sua imagem no cenário internacional, no poder de consumo e na consequente melhoria da qualidade de vida de sua população em geral. Por causa de tais transformações gerais, concomitantes e opostas, nos Estados Unidos e Brasil, talvez se esperasse observar o desestímulo à emigração internacional de brasileiros e a redução ou estagnação dos volumes de saída em direção à América do Norte.

Entretanto, notamos que o fluxo de brasileiros para os EUA permaneceu entre 2000 e 2010 com volume relativo e, mais especificamente, a circulação de migrantes, tanto internos quanto internacionais, continuou forte na microrregião de Governador Valadares. Aparentemente, o sistema migratório existente na região permaneceu operante devido à composição já consolidada das redes sociais, mercado e cultura migratória. Esta observação nos leva a rever as teorias da migração que consideram os aspectos relacionais e transacionais da dinâmica migratória (DE HAAS, 2010).

\section{Migração internacional e a MGV: uma revisão teórica sobre a perpetuação do sistema de migração existente na região}

Pode-se pensar sobre a mobilidade populacional ocorrida na microrregião de Governador Valadares a partir da perspectiva teórica elaborada por de Haas (2010), que considera as migrações parte de um processo social e econômico característico do desenvolvimento. Segundo o autor, os deslocamentos populacionais operariam como vetores estratégicos demográficos, ora como resposta, ora como motivação, para o desenvolvimento social e econômico das regiões. Para esta finalidade, em seu trabalho, de Haas classifica as teorias sobre as migrações organizadas em três grupos macroanalíticos: funcionalistas, estruturalistas e transacionais.

As teorias enquadradas como funcionalistas associam a migração a um modelo de equilíbrio econômico, exercendo forças de equalização considerando um mercado perfeito e sem constrangimentos estruturais para o desenvolvimento, apenas a força do mercado visando o equilíbrio. Uma primeira contribuição do conjunto funcionalista são os modelos de atração e expulsão (push and pull models) (RAVENSTEIN, 1885, 1889; LEE, 1966), que tratam a mobilidade como variável dependente para o desenvolvimento, considerando que a migração cessará em algum momento devido à tendência constante ao equilíbrio.

Segundo a modelagem macroeconômica analítica (LEWIS, 1954; HARRIS; TODARO, 1970), a migração ocorre por diferenciais de oferta e demanda de trabalho entre unidades espaciais, em que a atratividade de melhores salários faz com que os trabalhadores se desloquem de regiões com baixos salários para locais com escassez de mão de obra e altos salários. Já a abordagem microeconômica (SJAASTAD, 1962; TODARO, 1969) considera as 
migrações por meio das ações individuais, em que a autonomia do indivíduo the permite transitar livremente no mercado vis-à-vis o cumprimento de suas demandas (DAVIS, 1989). Na perspectiva dessa teoria, o indivíduo, como ator racional, decide migrar porque o cálculo do custo-benefício leva-o a esperar um retorno líquido positivo do movimento.

Borjas (1989) realiza avanços na abordagem microeconômica ao afirmar que é possível interpretar por meio de um framework de capital humano, em que a migração é considerada um investimento individual. A abordagem da Nova Economia da Migração desafia os pressupostos e conclusões da teoria econômica, colocando a visão fundamental de que as decisões de migrar não são feitas de forma isolada pelo indivíduo, mas sim por unidades mais amplas relacionadas às pessoas, basicamente famílias e domicílios. Seus membros agem coletivamente, não só para maximizar a renda esperada, mas também para minimizar os riscos relacionados às falhas no desenvolvimento dos mercados nos países de origem, em especial o mercado de trabalho (STARK; BLOOM, 1985; STARK; TAYLOR, 1989).

0 agrupamento de teorias enquadradas como funcionalistas, ao tratarem a migração fundamentalmente como um resultado dos diferenciais espaciais ligados ao desenvolvimento entre áreas de origem e destino, responde parcialmente ao fenômeno migratório ocorrido na MGV. Nesse sentido, assim como já havia sido observado por Soares (2002), é correto afirmar que a pobreza, os ciclos exploratórios não sustentáveis, a estagnação econômica, a hiperinflação, a crise econômica de 1980 e a reestruturação produtiva que ocorreram na região durante sua história foram fatores que estimularam o deslocamento internacional. Além disso, numa escala microanalítica, é razoável aceitar que os migrantes e seus familiares realizaram um cálculo racional dos riscos e benefícios desta travessia, considerando a maximização da renda e do capital humano dos envolvidos, tanto do indivíduo quanto da família. Todavia, é importante ressaltar que outras regiões brasileiras vivenciaram na época situações econômicas similares e não lograram a mesma experiência de mobilidade populacional.

A perspectiva teórica chamada de estruturalista assume a formação de um sistema socioeconômico determinante, segundo o qual os elementos que constituem as relações e funções que conduzem à migração são interdependentes (DE HAAS, 2010). As principais contribuições deste conjunto são a teoria de mercado de trabalho dual, o modelo histórico-estrutural, o neomarxista e o modelo de sistema-mundo (GERMANI, 1974; WALLERSTEIN, 1974; PIORE, 1979; SINGER, 1980; WOOD, 1982). De Haas considera que os modelos estruturalistas, ao valorizarem principalmente a contextualização histórica para compreender a dinâmica da mobilidade populacional, tendem a ser fortemente historicistas e macroanalíticos.

Assim como a abordagem funcionalista, os pressupostos estruturalistas contemplam parcialmente a explicação do fenômeno migratório da MGV. Não se pode negar que as condições estruturais de estagnação e racionalização dos mercados regional, nacional e internacional exerceram pressões migratórias junto aos habitantes da região. Entretanto, ao contrário do que aconteceu com a formação do sistema de migração México-EUA, 
resultante dos desdobramentos do Bracero Program, ${ }^{5}$ a emigração internacional no Brasil não se iniciou com base em acordos binacionais de recrutamento de mão de obra regulamentados por governos, e no caso específico da emigração massiva para os EUA ainda deve-se levar em conta o efeito singular das distâncias entre os territórios nacionais (FUSCO, 2000; SOARES, 2002).

De Haas (2010) destaca que a perspectiva transacional vai além das teorias anteriores. Os modelos transacionais seguem uma lógica evolutiva em que a modernização é a principal força motriz da mobilidade. As principais contribuições deste agrupamento teórico são os modelos transacionais tradicionais (ZELINSKY, 1971; SKELDON, 1997), seguidos dos “modelos de perpetuação" (MASSEY et al., 1987, 1993; MASSEY, 1990; GUILMOTO; SANDRON, 2001) e da teoria dos sistemas de migração (MABOGUNJE, 1970; FAWCETT, 1989; KRITZ; ZLOTNIK, 1992).

A perspectiva transacional ressalta que a migração é um processo amplo que relaciona diferentes atores (indivíduos, famílias, comunidades e lugares e espaços), eventos demográficos (crescimento populacional, mortalidade, envelhecimento, etc.) e econômicos (modernização econômica, reestruturação produtiva, divisão de trabalho, oscilações de mercado e outros). Por isso, a migração dependeria continuamente da formação de contextos em que as trocas e transições ocorrem dentro de um amplo projeto coletivo e relacional. A realidade experimentada na MGV pode ser mais bem compreendida se assumirmos a existência de um sistema de posições, reconhecendo uma estruturação hierárquica funcional entre as diferentes dimensões que formam o sistema migratório.

Com base nessa perspectiva, assume-se primeiramente que a migração ocorrida na região da MGV é um processo social, cujos deslocamentos são projetos socialmente orientados a partir da interação entre migrantes, não migrantes e regiões expulsoras e receptoras (MASSEY et al., 1987). Sendo a migração não apenas o efeito das escolhas exclusivas de um ator, ela constitui-se em um projeto coletivo, inserindo-se nas trocas entre os atores sociais que produzem as representações sociais em determinados territórios (SAYAD, 2000). Uma vez entendida como um processo social e coletivo, a migração pode ser integrada e operacionalizada formalmente a partir de um sistema de posições (FAWCETT, 1989; KRITZ; ZLOTNIK, 1992).

A teoria dos sistemas de migração fundamentalmente pressupõe que a migração altera historicamente as condições sociais, culturais, econômicas e institucionais tanto na origem quanto no destino (DE HAAS, 2010). Seu framework analítico considera o mercado de trabalho, a cultura da migração, as redes sociais e espaciais, os fatores de causação cumulativa, a hierarquia funcional do sistema-mundo e a transição das mobilidades (melhorias tecnológicas de comunicação e transporte, massificação dos deslocamentos internacionais, globalização,

\footnotetext{
$\overline{5}$ O Bracero Program foi um acordo bilateral de trabalho entre México e EUA com o fornecimento de mão de obra para a agricultura nos EUA, com a particularidade de que os agenciadores/recrutadores de trabalhadores eram regulamentados por agências governamentais dos dois países. Mais detalhes em 〈http://braceroarchive.org/about〉.
} 
integração global, dinamismo de curtas distâncias, circulação, etc.) (FAWCETT, 1989; KRITZ; ZLOTNIK, 1992).

De Haas (2010) destaca que a teoria dos sistemas de migração está intimamente relacionada aos pressupostos teóricos da análise de redes sociais. E tal associação permite admitir que o sistema da migração pode ser operacionalizado por meio de modelos de redes sociais (MASSEY et al., 1987, 1993). São as redes de interações sociais cotidianas que potencializam os fluxos migratórios e aumentam a probabilidade da realização de um deslocamento, reduzindo os custos e riscos da migração e influenciando o retorno líquido esperado (TILLY, 1990; FAZITO, 2005).

Nesse sentido, o projeto migratório será desenvolvido a partir de relações cotidianas entre diversos atores sociais posicionados estrategicamente na estrutura social (FAZITO; SOARES, 2010). Para o caso da MGV, as redes sociais que se formaram entre origem e destino contribuíram para que se desenvolvesse ao longo dos anos um sistema de migração estruturado, como observado também em outras regiões brasileiras, por exemplo, os municípios de Criciúma e Goiânia (MARTES, 2000; ASSIS, 2003; FUSCO, 2006). 0 emigrante retornado é fundamental neste cenário para perpetuação do sistema por meio do suporte social transmitido entre seus pares. Ao retornar, este indivíduo caracteriza-se como um ator dotado de capital social qualificado em relação aos processos migratórios. Dessa forma, ele pode assumir papéis de suporte financeiro, psicológico e de intermediação entre contatos para que migrantes em potencial consigam a retirada de documentos, realização da travessia (legal ou não), moradia e emprego em terras estrangeiras. Além disso, ao ocupar uma posição estrutural privilegiada no sistema da migração, alguns retornados especializam tal suporte, tornando-se agenciadores (brokers) da chamada indústria da migração ilegal.

Os emigrantes retornados, além de serem atores fundamentais na operacionalização de um mercado ilegal da migração, também são os maiores responsáveis pela difusão de uma cultura migratória. As remessas enviadas quando eram imigrantes, por um lado, permitiriam combater a pobreza, aumentar o consumo e melhorar o padrão de vida dos que ficaram e, por outro, materializariam o sucesso do projeto migratório para todos os pares que compartilhassem de alguma maneira o sucesso de sua empreitada, afetando diretamente a propensão futura de um indivíduo a migrar. 0 espraiamento das representações contidas em uma “cultura migratória” associaria a migração internacional e, especialmente, sua concretude na figura do retornado internacional ao sucesso pessoal em que a migração passa a ser percebida "normativamente" como uma alternativa estratégica de sobrevivência quase compulsória, como se a imobilidade estivesse associada ao fracasso (KANDEL; MASSEY, 2002; FAZITO, 2010; DE HAAS, 2006, 2010).

0 arcabouço das redes sociais de migração contribui significativamente para compreender as singularidades do processo migratório internacional existente na região. 0 fácil acesso a um processo de travessia, as informações e recursos transmitidos pelos retornados e o desejo de migrar elevado a um caráter "cultural" expressariam melhor a condição anterior e essencial para a realização de um projeto migratório (KANDEL; MASSEY, 
2002). Nessa lógica, a concretização do projeto migratório está associada ao capital social que o migrante em potencial adquire a partir de suas relações entre familiares, amigos, retornados e outras instituições que lhe garantam acesso a recursos e informações, visando a redução de riscos e maximização de ganhos inerentes aos deslocamentos populacionais (TILLY, 1990; LIN, 2001; FAZITO; SOARES, 2010).

\section{A dinâmica migratória na MGV na década de 2000 e nos dias atuais: contração, manutenção ou expansão?}

Aqui procuramos apresentar o quadro demográfico mais imediato e objetivo das trocas migratórias na MGV ocorridas na década de 2000, em relação à dinâmica intrarregional, interna e internacional, e compará-lo com as tendências observadas nos censos demográficos das últimas décadas.

Nos anos 1940 e 1950 a região de Governador Valadares vivia seu apogeu econômico e recebia muitos trabalhadores do Nordeste brasileiro e regiões vizinhas. Nas duas décadas seguintes, a população continuou crescendo a taxas menores, configurando-se ainda como um território de atração de migrantes, mesmo que no estado de Minas Gerais se percebesse o oposto (SOARES, 2002). A fragilidade econômica do país na década de 1970 e o esgotamento dos veios extrativistas na região refletiram diretamente na configuração migratória da MGV, intensificando as perdas populacionais. Entre 1970 e 1980 as perdas líquidas internas ultrapassaram 64 mil pessoas, diminuindo para 23 mil, entre 1981 e 1991, e para 14 mil, entre 1991 e 2000 (IBGE, 2002). Tais perdas observadas a partir dos censos demográficos dizem respeito à mobilidade dentro da circunscrição nacional. Soares (2002) aponta que a aparente contração do saldo migratório pode ter influência direta da emigração internacional não captada pelos dados censitários.

A tendência decrescente das perdas líquidas internas observadas nas últimas décadas na região em relação à dinâmica interna não se manteve entre 2000 e 2010 . Registrou-se, nessa década, uma perda líquida em torno de 18 mil pessoas, mantendo-se a tendência histórica dos deslocamentos. Por um lado, Belo Horizonte, Ipatinga e Teófilo Otoni foram os principais municípios que cederam população à MGV; por outro, os maiores centros receptores de cidadãos da região foram aqueles que formam as regiões metropolitanas de Belo Horizonte e Grande Vitória e a região do Vale do Aço (IBGE, 2011).

0 balanço populacional entre imigrantes e emigrantes da MGV, no quinquênio $2005 / 2010$, obtido por meio de dados de data fixa, apresentou um saldo migratório negativo de 9.505 pessoas. Já para o primeiro quinquênio (2000/2005), utilizando informações sobre lugar e duração de última residência, os volumes de migrantes apontaram uma diferença negativa de 8.316 habitantes na MGV (IBGE, 2011).

A composição dos fluxos migratórios sumarizada na Tabela 1 reforça uma característica comum nos estudos de migração laboral em que predominam nos deslocamentos aqueles indivíduos jovens em idade produtiva. Aparentemente, os significativos saldos negativos 
nos grupos etários entre 20 e 39 anos podem estar relacionados a uma economia local estagnada e à consequente falta de oportunidades no mercado de trabalho.

TABELA 1

Imigrantes e emigrantes (1) internos, por sexo, segundo grupos etários Microrregião de Governador Valadares - 2005/2010

\begin{tabular}{|c|c|c|c|c|c|c|c|c|c|}
\hline \multirow{2}{*}{$\begin{array}{c}\text { Grupos } \\
\text { etários } \\
\text { (em anos) }\end{array}$} & \multicolumn{3}{|c|}{ Imigrantes } & \multicolumn{3}{|c|}{ Emigrantes } & \multicolumn{3}{|c|}{ Saldo migratório } \\
\hline & Homens & Mulheres & Total & Homens & Mulheres & Total & Homens & Mulheres & Total \\
\hline 5 a 9 & 908 & 859 & 1.767 & 1.276 & 1.165 & 2.441 & -368 & -306 & -674 \\
\hline 10 a 14 & 887 & 856 & 1.743 & 1.175 & 1.322 & 2.497 & -288 & -466 & -754 \\
\hline 15 a 19 & 905 & 1.119 & 2.024 & 1.447 & 1.598 & 3.045 & -542 & -479 & -1.021 \\
\hline 20 a 24 & 1.029 & 1.077 & 2.106 & 1.867 & 2.320 & 4.187 & -838 & -1243 & -2.081 \\
\hline 25 a 29 & 1.027 & 1.242 & 2.269 & 1.496 & 1.984 & 3.480 & -469 & -742 & -1.211 \\
\hline 30 a 34 & 961 & 875 & 1.836 & 1.456 & 1.565 & 3.021 & -495 & -690 & -1.185 \\
\hline 35 a 39 & 785 & 832 & 1.617 & 1.102 & 1.232 & 2.334 & -317 & -400 & -717 \\
\hline 40 a 44 & 563 & 603 & 1.166 & 922 & 740 & 1.662 & -359 & -137 & -496 \\
\hline 45 a 49 & 417 & 488 & 905 & 571 & 515 & 1.086 & -154 & -27 & -181 \\
\hline 50 a 54 & 389 & 282 & 671 & 380 & 630 & 1.010 & 9 & -348 & -339 \\
\hline 55 a 59 & 168 & 277 & 445 & 373 & 324 & 697 & -205 & -47 & -252 \\
\hline 60 a 64 & 205 & 168 & 373 & 210 & 308 & 518 & -5 & -140 & -145 \\
\hline 65 a 69 & 157 & 156 & 313 & 235 & 251 & 486 & -78 & -95 & -173 \\
\hline 70 a 74 & 129 & 85 & 214 & 103 & 170 & 273 & 26 & -85 & -59 \\
\hline 75 a 79 & 76 & 59 & 135 & 134 & 72 & 206 & -58 & -13 & -71 \\
\hline 80 ou mais & 54 & 171 & 225 & 154 & 217 & 371 & -100 & -46 & -146 \\
\hline Total & 8.660 & 9.149 & 17.809 & 12.901 & 14.413 & 27.314 & -4.241 & -5.264 & -9.505 \\
\hline
\end{tabular}

Fonte: IBGE. Censo Demográfico 2010.

(1) Dados de data fixa.

A superioridade feminina nos deslocamentos internos, apontada na Tabela 1, apresentou uma distribuição relativa compatível com a observada nas últimas décadas. De fato, a composição etária e por sexo verificada no último quinquênio na MGV sugere que a dinâmica interna na década de 2000 manteve-se de acordo com o padrão histórico da região, permanecendo inclusive as regiões mais significativas de origem e destino dos migrantes.

Durante os anos 2000 ocorreram eventos críticos nos EUA que exerceram impacto direto sobre o fluxo de migrantes internacionais valadarenses, em especial sobre a comunidade de imigrantes brasileiros residentes nos EUA. Um primeiro evento refere-se ao aumento da fiscalização americana junto aos imigrantes irregulares após o atentado de 11 de setembro de 2001, o que dificultou a permanência de diversos indivíduos que mantinham uma condição irregular no país e levou a uma política de deportações em massa entre 2004 e 2005 pelo governo norte-americano (FAZITO; SOARES, 2014). Já o segundo evento refere-se à forte crise econômica que se instalou nos EUA na segunda metade da década, afetando diretamente o crédito e os investimentos dos migrantes.

Então, aparentemente, tanto o endurecimento da fiscalização de migrantes quanto a crise econômica americana podem ter contribuído para um fluxo maior de retornados no segundo quinquênio. A MGV recebeu cerca de cinco mil pessoas que migraram de outro país 
durante a década de 2000 , sendo que $16,7 \%$ destes deslocamentos ocorreram no primeiro quinquênio e $83,4 \%$ no segundo. Os Estados Unidos e Portugal, justamente os países com maior estoque de imigrantes brasileiros oriundos da MGV, foram aqueles com maior participação no envio de migrantes, com, respectivamente, 75,9\% e 14,7\% (IBGE, 2011).

Apesar de as entradas de migrantes de outros países na MGV terem sido significativamente maiores no segundo quinquênio, é importante destacar o diferencial de idade entre retornados e estrangeiros. Cerca de $80 \%$ dos estrangeiros (646 indivíduos) possuíam até 15 anos de idade, sugerindo que muitos destes sejam efeitos indiretos da migração, ou seja, filhos dos emigrantes brasileiros que ora retornam com sua família constituída em outras terras. 0 Gráfico 1 mostra os diferenciais por sexo e idade com os dados de migração de última etapa para imigrantes internacionais da MGV, estrangeiros e retornados, desagregados por quinquênios.

GRÁFICO 1

Número de imigrantes internacionais, por sexo, segundo grupos etários Microrregião de Governador Valadares - 2005-2010

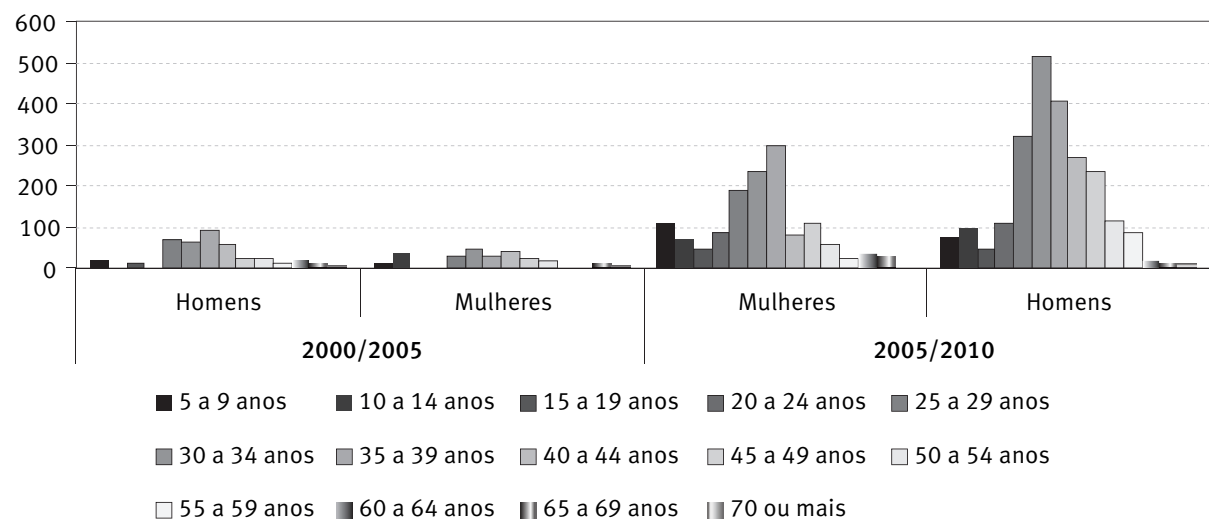

Fonte: IBGE. Censo Demográfico 2010.

Outro fator importante é o diferencial de sexo, com a imigração masculina respondendo por $62,5 \%$ do total e com picos nos grupos etários compreendidos entre 30 e 39 anos. A partir dos dados disponíveis não é possível afirmar precisamente os motivos pelos quais os migrantes valadarenses retornaram de forma mais concentrada no segundo quinquênio da década de 2000. Entretanto, como a crise americana iniciou-se justamente no setor imobiliário, acreditamos que os trabalhadores brasileiros, principalmente homens, sejam provavelmente os primeiros e os principais afetados por se dedicarem principalmente a atividades profissionais ligadas à construção civil.

A crise econômica americana iniciada em 2006 com o estouro da bolha imobiliária parece ter provocado a queda do fluxo de remessas internacionais dos Estados Unidos para o Brasil até o fim da década. O Boletim do Banco Central do Brasil (2013) ${ }^{6}$ sobre os

$\overline{{ }^{6} \text { Os boletins financeiros }}$ anuais do Banco Central do Brasil podem ser acessados em 〈http://www.bcb.gov.br/?boletim〉. 
envios de remessas do exterior para manutenção de residentes no Brasil apontam que, de 2006 (USD 1,415 bilhão) a 2010 (USD 634 milhões), o volume de remessas sofreu retrações gradativas anuais. Este declínio afetou diretamente o mercado da microrregião de Governador Valadares devido à significativa contribuição das remessas internacionais na dinâmica econômica da região (SIQUEIRA, 2008). Para uma região que já vivia uma paralisia econômica, esse cenário provocou uma estagnação ainda maior, afetando principalmente os setores imobiliário (especialmente o setor da construção civil), comercial e de prestação de serviços (MARTES; SOARES, 2006).

Numa perspectiva histórica da dinâmica migratória da MGV, estimativas produzidas por Soares (2002), para o período 1986-1991, apontam que o volume de emigrantes internacionais que partiram do estado de Minas Gerais para outro país foi em torno de 175 mil indivíduos. Diversos autores indicam que foi nesse período que ocorreu o maior boom emigratório internacional na região de Governador Valadares (SALES, 1999; ASSIS, 1999; FUSCO, 2000). As análises de Soares mostram que, naquele quinquênio, 7.113 homens e 5.205 mulheres saíram da MGV e foram morar em outro país.

Embora não existam estimativas específicas para a região no período 1991-2000, Garcia (2013), ao produzir análises para todas as regiões brasileiras, mostrou que no quinquênio 1995/2000, em Minas Gerais, cerca de 27 mil indivíduos emigraram para outro país. Apesar da dificuldade de comparação entre os dados dos dois autores que utilizaram o mesmo método, a grande diferença nos resultados entre uma década e outra sugere uma diminuição significativa no fluxo emigratório internacional de brasileiros durante o período.

O Censo Demográfico de 2010 incorporou ao questionário do universo um conjunto de perguntas sobre emigrantes internacionais, que possibilitam uma análise direta das informações referentes a este tipo de deslocamento. Os dados apontaram que, durante a década de 2000, 4.813 cidadãos da região emigraram para o exterior, tendo os Estados Unidos (66\%) e Portugal (23\%) como os principais destinos (IBGE, 2011). Como já destacado anteriormente, estes dois países são indicados em pesquisas, respectivamente, como rotas principal e secundária dos fluxos regionais (PEREIRA; SIQUEIRA, 2013; SANTOS; PINHO, 2014).

Os dados apurados pelo levantamento pioneiro realizado pelo Censo Demográfico de 2010 sugerem a preservação do fluxo de um significativo volume de emigrantes internacionais a partir da MGV. É importante ressaltar que as informações dos emigrantes são coletadas a partir de indivíduos que permaneceram no país e que haviam residido junto ao emigrante e, por isso, há situações que possibilitam a introdução de erros na enumeração, podendo adicionar ou subtrair ao número de emigrantes, isto é, erros por falta ou por excesso (CUNHA, 2012).

Os erros por falta ocorrem em situações de impossibilidade de enumeração dos emigrantes quando, por exemplo, todos os moradores de um domicílio efetivaram a emigração internacional. Por outro lado, os erros por excesso aparecem quando há dupla contagem de emigrantes, como em casos de desmembramento de um domicílio, em que o emigrante 
é reportado em cada um dos novos domicílios. É desconhecida a magnitude de tais erros, não sendo possível afirmar que estes tendem a se compensar.

No caso da MGV, assume-se principalmente que os dados coletados no Censo 2010 tendem a confirmar a continuidade do fluxo tradicional de migrantes entre origem e destino na década, bem como oferecem uma representação plausível sobre a forma da distribuição destes por países de destino.

Análises produzidas por Soares, Fazito e Farias (2012), com dados coletados em 2010, utilizando o método de ampliação das redes pessoais (scale-up e summation), buscaram oferecer estimativas do tamanho médio das redes pessoais e, a partir delas, mensurar o tamanho de determinada subpopulação, no caso, os emigrantes internacionais da MGV. 0 total de emigrantes internacionais encontrados correspondeu a 6.642 pessoas que, segundo os autores, correspondem ao "estoque de emigrantes internacionais num período específico, apenas um ano, e leva necessariamente em conta indivíduos que mantêm interações sociais ativas entre origem e destino", sugerindo que cerca de $2,6 \%$ da população da região possui o "raro" atributo de ser emigrante internacional (SOARES; FAZITO; FARIAS, 2012, p. 12).

Apesar de a imigração internacional na região ter apresentado um aumento significativo no segundo quinquênio, apontando para fatores externos que conduziram um significativo movimento de retorno, análises dos dados censitários de forma direta $^{7}$ e indireta ${ }^{8}$ (ver Tabelas 1 e 2 do Apêndice, que contêm estimativas de emigrantes internacionais entre 2000 e 2010 para homens e mulheres, por resíduo) e de pesquisas in loco (SOARES; FAZITO; FARIAS, 2012) indicam que a emigração internacional continuou expressiva.

0 aspecto mais interessante dessas observações é que os cidadãos da região continuam indo e vindo, mantendo a rede social migratória ativa mesmo em condições aparentemente adversas. As rotas permanecem abertas e ativadas, se ajustando constantemente aos contextos local e global da dinâmica econômica e demográfica.

Desse modo, em certo sentido, na década de 2000, o sistema de migração estruturado pelas redes sociais pessoais e institucionais que interconectam os indivíduos num mercado ampliado da migração irregular e a cultura da migração, que se sustenta nas representações sociais históricas das relações estabelecidas entre os Estados Unidos e a região, no fluxo de remessas do emigrado e no estilo de vida do retornado e seus familiares, aparentemente atuaram como importantes mecanismos para preservação e reprodução dos fluxos de emigração internacional na década.

\footnotetext{
${ }_{7}^{7}$ Análises obtidas por meio da combinação entre os quesitos sobre migração no Censo Demográfico de 2010 (IBGE, 2011).

${ }^{8}$ A técnica indireta consiste, fundamentalmente, na análise residual produzida pela diferença entre a população observada e a população esperada, sendo que seu resultado corresponde apenas aos saldos migratórios, sem desagregação entre imigrantes e emigrantes. Para o caso de uma microrregião específica, deve-se incluir os diferenciais produzidos pela dinâmica de mobilidade interna no período. Orientações mais detalhadas sobre aplicação da técnica podem ser obtidas nos trabalhos de Soares (2002), Carvalho (1996) e Garcia (2013).
} 


\section{Considerações finais}

O pensamento teórico a partir da relação entre migração e desenvolvimento considera que a representatividade do fenômeno da emigração internacional na região de Governador Valadares se explica por diversos fatores. De um lado, a pobreza, os ciclos exploratórios não sustentáveis, a estagnação econômica, a hiperinflação, a crise econômica de 1980 e a reestruturação produtiva seriam fatores dentro do âmbito econômico-funcional que teriam contribuído para o fluxo migratório internacional. De outro, as condições estruturais de estagnação e racionalização dos mercados certamente exerceram pressões migratórias junto aos cidadãos que viviam na região (SOARES, 2002).

Sobretudo, a emigração internacional iniciada no fim dos anos 1960 e consolidada na década de 1980 baseia-se num sistema de migração estruturado composto por redes sociais e instituições que contribuem para a perpetuação do deslocamento. 0 desenvolvimento da emigração ao longo dos anos alterou a dinâmica econômica interna e fez emergir uma rede social migratória constituída de redes pessoais entre emigrantes, retornados, familiares, agentes e instituições. A ampliação das restrições à travessia impostas pelos Estados Unidos motivou uma adaptação deste sistema, proporcionando o fortalecimento da chamada "indústria da migração ilegal” na região.

A década de 2000 foi marcada pelo aumento da fiscalização dos emigrantes irregulares e pela grande crise financeira do mercado imobiliário nos Estados Unidos. Dados censitários apontaram para um significativo retorno dos migrantes valadarenses e seus filhos, sugerindo que tal movimento tenha sido motivado pelos eventos críticos americanos e pelo novo cenário econômico brasileiro, que proporcionou uma melhora da qualidade de vida de seus cidadãos.

Entretanto, análises a partir de dados censitários, estimativas indiretas e pesquisas in loco sugerem também que a emigração de cidadãos da região continuou a ocorrer com relativa força. Em outras palavras, aparentemente, os Estados Unidos continuaram como destino importante e preferencial mesmo tendo passado por uma forte crise global. Dado o contexto singular da região da MGV, com as estruturas já estabelecidas (redes sociais, mercado e cultura migratória) e a falta de perspectivas de inserção e mobilidade social em uma região de origem historicamente marcada pela estagnação econômica, é plausível considerar que a população da região poderia ter percebido as "oportunidades" oferecidas pela emigração positivamente, mesmo considerando um cenário internacional “depreciado" em relação a tempos anteriormente vividos.

Se, por um lado, as adversidades ocorridas nos Estados Unidos na década de 2000 impactaram positivamente o retorno dos emigrantes e reduziram o fluxo de remessas, por outro, é provável que não tenham sido capazes de esgotar o sistema migratório e seus mecanismos reticulares já estabelecidos e adaptados ao contexto regional. 


\section{Referências}

ASSIS, G. Estar aqui..., estar lá...: uma cartografia da emigração valadarense para os EUA. In: REIS, R. R.; SALES, T. (Org.). Cenas do Brasil migrante. São Paulo: Boitempo, 1999. p. 125-166.

ASSIS, G. De Criciúma para o mundo: os novos fluxos da população brasileira: gênero e rearranjos familiares. In: MARTES, A. C. B.; FLEISCHER, S. (Org.). Fronteiras cruzadas: etnicidade, gênero e redes sociais. São Paulo: Paz e Terra, 2003. p. 199-230.

BANCO CENTRAL DO BRASIL. Boletim do Banco Central do Brasil - Relatório 2013. Brasília: Departamento Econômico (Depec), 2013. Disponível em: 〈http://www.bcb.gov.br/pec/boletim/ banual2013/rel2013p.pdf〉.

BORJAS, G. J. Economic theory and international migration. International Migration Review, V. 23, n. 3, p. 457-485, 1989.

BREMAN, J. Seasonal migration and co-operative capitalism: the crushing of cane and of labour by the sugar factories of Bardoli, South Gujarat. Journal of Peasant Studies, v. 6. n. 2, p. 168209, 1979.

CARVALHO, J. A. M. O saldo dos fluxos migratórios internacionais do Brasil na década de 80: uma tentativa de estimação. Revista Brasileira de Estudos de População, v. 13, n. 1, p. 3-14, 1996.

CARVALHO, J. A. M.; MAGALHAES, M. V.; GARCIA, R. A.; SOARES, W. Sinuosos caminhos para estimação dos emigrantes internacionais de 1986/1991 e de 1991/1996 e saldos migratórios: os qüinqüênios entre 1981 e 1996 das Unidades da Federação Brasileira. In: ENCONTRO NACIONAL DE ESTUDOS POPULACIONAIS, 12, Caxambu, 2000. Anais... Rio de Janeiro: Abep, 2000.

CUNHA, J. M. P. Retratos da mobilidade espacial no Brasil: os censos demográficos como fonte de dados. Rev. Inter. Mob. Hum, ano XX, n. 39, p. 29-50, jul./dez. 2012.

DAVIS, K. Social science approaches to international migration. In: TEITELBAUM, M.; WINTER, J. (Ed.). Population and resources in western intellectual traditions. Cambridge: Cambridge University, UK., 1989.

DE HAAS, H. The social and cultural impacts of international migration on Moroccan sending communities: a review. In: BOS, P. H. F.; FRITSCHY, W. (Ed.). Morocco and the Netherlands: society, economy, culture. Amsterdam: VU Publishers, 2006.

. Migration and development: a theoretical perspective. International Migration Review, v. 44, n. 1, p. 227-264, 2010.

EELENS, F.; SPECKMANN, J. D. Recruitment of labor migrants in the middle east. International Migration Review, v. 24, n. 90, p. 297-322, 1990.

ESPINDOLA, H. S. Sertão do Rio Doce. Bauru: Edusc, 2005.

FAWCETT, J. T. Networks, linkages, and migration systems. International Migration Review, v. 23, n. 3, p. 671-80, 1989.

FAZITO, D. Reflexões sobre os sistemas de migração internacional: proposta para uma análise estrutural dos mecanismos intermediários. Tese (Doutorado em Demografia) - Centro de Desenvolvimento e Planejamento Regional, Universidade Federal de Minas Gerais, Belo Horizonte, 2005.

FAZITO, D.; SOARES, W. Capital social, análise de redes e os mecanismos intermediários do sistema migratório Brasil/EUA. Revista Geografias, v. 6, n. 1, p. 27-41, 2010.

. The industry of illegal migration: social network analysis of the Brazil-US migration system. International Migration, v. 53, n. 6, p.183-204, 2014. 
FUSCO, W. Redes sociais na migração internacional: o caso de Governador Valadares. Dissertação (Mestrado em Sociologia) - Universidade Estadual de Campinas (Unicamp), Campinas, 2000.

. Capital cordial: a reciprocidade entre os imigrantes brasileiros nos Estados Unidos. Tese (Doutorado em Demografia) - Universidade Estadual de Campinas (Unicamp), Campinas, 2005.

Conexão origem-destino: migrantes brasileiros no exterior. In: ENCONTRO NACIONAL DE ESTUDOS POPULACIONAIS, 15, Caxambu, 2006. Anais... Rio de Janeiro: Abep, 2006.

FUSCO, W.; SOUCHAUD, S. De volta para casa: a distribuição dos brasileiros retornados do exterior. Confins, v. 9, n. 1, 2010.

GARCIA, R. A. Estimativas dos emigrantes internacionais do Brasil entre 1995 e 2000: uma aplicação do método das razões intercensitárias de sobrevivência. Revista Brasileira de Estudos de População, v. 30, n. 1, p. 99-123, jan./jun. 2013.

GERMANI, G. Sociologia da modernização: estudos teóricos, metodológicos e aplicados a América Latina. São Paulo: Mestre Jou, 1974.

GOZA, F. Brazilian immigration to North America. International Migration Review, v. 28, n. 1, p. 136-152, 1994.

GUILMOTO, C. Z.; SANDRON, F. The internal dynamics of migration networks in developing countries. Population: an English Selection, v. 13, n. 2, p. 135-164, 2001.

HARRIS, J. R.; TODARO, M. P. Migration, unemployment and development: a two-sector analysis. The American Economic Review, v. 60, n. 1, p. 126-142, 1970.

IBGE - Instituto Brasileiro de Geografia e Estatística. Censo Demográfico Brasileiro 2000. Rio de Janeiro: IBGE, 2002.

. Censo Demográfico Brasileiro 2010. Rio de Janeiro: IBGE, 2011.

KANDEL, W.; MASSEY, D. S. The culture of Mexican migration: a theoretical and empirical analysis. Social Forces, v. 80, n. 3, p. 981-1004, 2002.

KRITZ, M.; ZLOTNIK, H. Global interactions: migration systems, processes and policies. In: KRITZ, M. et al. (Ed.). International migration systems, a global approach. Oxford: Clarendon, 1992. p. 1-16.

LEE, E. S. A theory of migration. Demography, v. 3, n. 1, p. 47-57, 1966.

LEWIS, W. A. Economic development with unlimited supplies of labour. Manchester School of Economic and Social Studies, v. 22, n. 1, p. 139-91, 1954.

LIN, N. Social capital. A theory of social structure and action. Cambridge: Cambridge University Press, 2001.

MABOGUNJE, A. L. Systems approach to a theory of rural-urban migration. Geographical Analysis, v. 2, n. 1, p. 1-18, 1970.

MARGOLIS, M. Little Brazil: imigrantes brasileiros em Nova York. Campinas: Papirus, 1994.

MARTES, A. C. B. Brasileiros nos Estados Unidos: um estudo sobre imigrantes em Massachusetts. São Paulo: Paz e Terra, 2000.

MARTES, A. C. B.; SOARES, W. Remessas de recursos dos imigrantes. Estudos Avançados, v. 20, n. 57, p. 41-54, 2006.

MASSEY, D. S. Social structure, household strategies, and the cumulative causation of migration. Population Index, v. 56, n. 1, p. 3-26, 1990. 
MASSEY, D. S. et al. Return to Aztlan, the social process of international migration from Western Mexico. Berkeley: University of California, 1987.

Theories of international migration: a review and appraisal. Population and Development Review, v. 19, n. 3, p. 431-466, 1993.

PATARRA, N. L.; BAENINGER, R. Migrações internacionais recentes: o caso do Brasil. In: PATARRA, N. L. (Org.). Emigração e imigração internacionais no Brasil contemporâneo. São Paulo: FNUAP, 1995. p. 79-87.

PEREIRA, S.; SIQUEIRA, S. Migração, retorno e circularidade: evidência da Europa e Estados Unidos. Revista Interdisciplinar da Mobilidade Humana - REMHu, v. 21, n. 41, p. 117-138, 2013.

PIORE, M. Birds of passage: migrant labor in industrial societies. Cambridge: Cambridge University Press, 1979.

RAVENSTEIN, E. G. The laws of migration. Journal of the Royal Statistical Society, v. 48, n. 1, p. 167-227, 1885.

1889.

. The laws of migration. Journal of the Royal Statistical Society, v. 52, n. 1, p. 214-301,

SALES, T. Brasileiros longe de casa. São Paulo: Cortez, 1999.

SANTOS, M.; PINHO, F. A emigração portuguesa em contexto de crise econômica. In: ENCONTRO NACIONAL DE ESTUDOS POPULACIONAIS, 19, Águas de Lindóia, 2014. Anais... Rio de Janeiro: Abep, 2014.

SAYAD, A. O retorno: elemento constitutivo da condição do migrante. Revista Travessia, v. 13, n. 1, p. 7-32, 2000.

SINGER, P. Migrações internas: considerações teóricas sobre o seu estado. In: MOURA, H. A. (Org.). Migração interna, textos selecionados. Fortaleza: BNB/Entene, 1980, 1976. p. 211-244.

SIQUEIRA, S. Migrantes e empreendimentos na microrregião de Governador Valadares: sonhos e frustrações no retorno. Tese (Doutorado em Sociologia e Política) - Faculdade de Filosofia e Ciências Humanas, Universidade Federal de Minas Gerais, Belo Horizonte, 2006.

Migracion y las distintas formas de retorno al suelo natal. Una perspectiva transnacional. In: SIMPOSIO INTERNACIONAL NUEVOS RETOS DEL TRANSNACIONALISMO EN EL ESTUDIO DE LAS MIGRACIONES, Barcelona, 2008. Anais... Barcelona: Gedime, 2008.

SJAASTAD, L. A. The costs and returns of human migration. The Journal of Political Economy, v. 70, n. 5, p. 80-93, 1962.

SKELDON, R. Migration and development: a global perspective. Essex: Longman, 1997.

SINGHANETRA-RENARD, A. The mobilization of labour migrants in Thailand: personal links and facilitating networks. In: KRITZ, M. et al. (Ed.). International migration systems, a global approach. Oxford: Clarendon, 1992. p. 190-204.

SOARES, W. Da metáfora à substância: redes sociais, redes migratórias e migração nacional e internacional em Valadares e Ipatinga. 2002. 344 f. Tese (Doutorado em Demografia) - Centro de Desenvolvimento e Planejamento Regional, Universidade Federal de Minas Gerais, Belo Horizonte, 2002.

SOARES, W.; FAZITO, D.; FARIA, S. D. Do método para estimar o tamanho médio das redes pessoais e o tamanho de populações difíceis de contar. Revista Brasileira de Estudos de População, v. 29, n. 1, p. 101-115, jan./jun. 2012. 
SOUSA, L.; DIAS, C. A. Microrregião de Governador Valadares: a busca de uma identidade territorial para uma região em crise. In: SEMINÁRIO DE ECONOMIA MINEIRA, 13, Diamantina, 2010. Anais... Belo Horizonte: Cedeplar-UFMG, 2010.

STARK, O.; BLOOM, D. E. The new economics of labor migration. The American Economic Review, V. 75, n. 2, p. 173-178, 1985.

STARK, O.; TAYLOR, J. E. Relative deprivation and international migration. Demography, v. 26, n. 1, p. 1-14, 1989.

TILLY, C. Transplanted networks. In: YANS-MCLAUGHLIN, V. (Org.). Immigration reconsidered: history, sociology, and politics. London, New York: Oxford University, 1990.

TODARO, M. P. A model of labor migration and urban unemployment in less-developed countries. American Economic Review. v. 59, n. 1, p. 138-48, 1969.

WALLERSTEIN, I. The modern world system i, capitalist agriculture and the origins of the European world economy in the sixteenth century. New York: Academic Press, 1974.

WOOD, C. H. Equilibrium and historical-structural perspectives on migration. International Migration Review, v. 16, n. 2, p. 298-319, 1982.

ZELINSKYZ, W. The hypothesis of the mobility transition. Geographical Review, v. 61, n. 1, p. 219-49, 1971.

\section{Sobre os autores}

Leonardo Gomes de Sousa é doutor em Demografia pelo Centro de Desenvolvimento e Planejamento Regional, Universidade Federal de Minas Gerais (Cedeplar/UFMG).

Dimitri Fazito é doutor em Demografia pelo Centro de Desenvolvimento e Planejamento Regional, Universidade Federal de Minas Gerais (Cedeplar/UFMG). Professor adjunto do Departamento de Sociologia da UFMG.

\section{Endereço para correspondência}

Leonardo Gomes de Sousa

Faculdade de Ciências Econômicas

Departamento de Demografia, Universidade Federal de Minas Gerais

Av. Antônio Carlos, 6.627 - campus Pampulha

31270-901 - Belo Horizonte-MG, Brasil

Dimitri Fazito

Faculdade de Ciências Econômicas

Departamento de Sociologia, Universidade Federal de Minas Gerais

Av. Antônio Carlos, 6.627 - campus Pampulha

31270-901 - Belo Horizonte-MG, Brasil 


\begin{abstract}
A study on the dynamics of international migration between the Governador Valadares Microregion and the United States, 2000-2010

The microregion of Governador Valadares (MGV) is the most representative Brazilian regional area regarding out-migration of Brazilians to the United States. However, in the 2000 decade, new and adverse global changes that economically would affect both the origin and destination settings implying in a probable reduction or even a complete interruption of out-migration flows. This paper aims to analyze the hypothesis that, even in an apparent adverse scenario, international out-migration continued with considerable intensity during the first half of the 2000 decade. The formation of the international out-migration flows from the MGV to the USA and its adherence to the migration theories was analyzed, and also provided an empirical investigation considering the stocks and flows of international migrants within the Brazil-USA migration system. The results show that in the 2000's the structured migration system, based and reinforced by the personal migration networks in the region, exerted a considerable force towards the regulation of the out-migration flows.
\end{abstract}

Keywords: International migration. United States. Governador Valadares microregion.

\title{
Resumen
}

Un estudio sobre los aspectos de la dinámica de la migración internacional entre la microrregión de Governador Valadares y Estados Unidos, 2000-2010

La microrregión de Governador Valadares (MGV) es la más representativa en el ámbito de la emigración internacional de los brasileños a los Estados Unidos. Sin embargo en la primera década del siglo XXI nuevos y adversos cambios globales que económicamente podrían afectar ambos las regiones de origen y destino de los migrantes, probablemente conducirían a una disminución o hasta un estancamiento del flujo de migrantes. Este artículo busca analizar la hipótesis de que, incluso en un escenario aparentemente adverso, la migración continuó en la región con fuerza considerable durante los primeros años de la década de 2000. Para esto, se procuro entender cómo se ha configurado el estado de la migración internacional hacia Estados Unidos desde Governador Valadares y su adherencia explicativa con las teorías de la migración, así como la verificación objetiva de los volúmenes y flujos de migrantes que figuran en el sistema migratorio. Se observó que entre 2000 y 2010 el sistema de migración estructurado, basado y reforzado por las redes sociales personales ejerció fuerza considerable en la regulación del flujo emigratorio.

Palabras clave: Migración internacional. EEUU. Microrregión de Governador Valadares. 


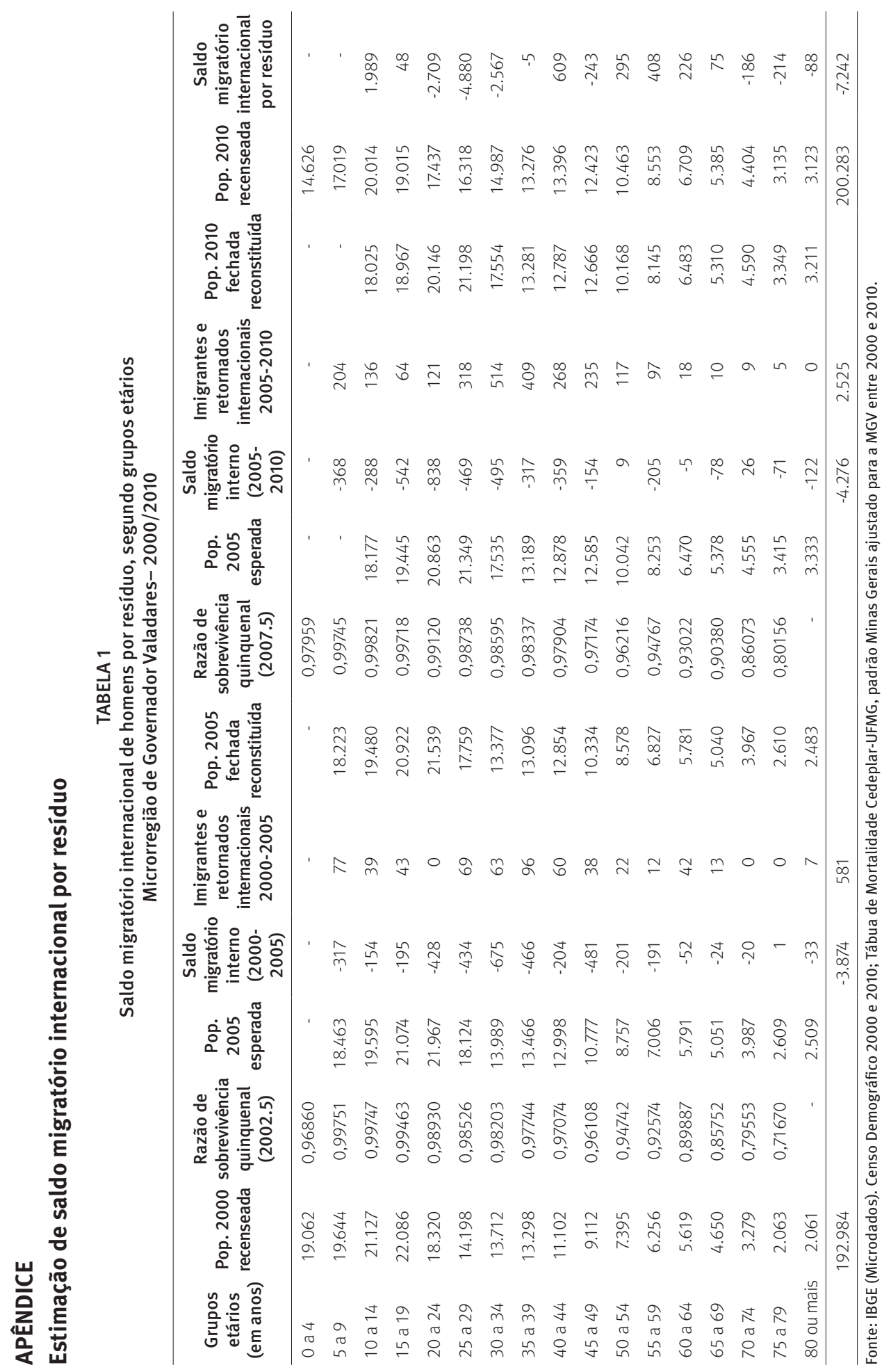




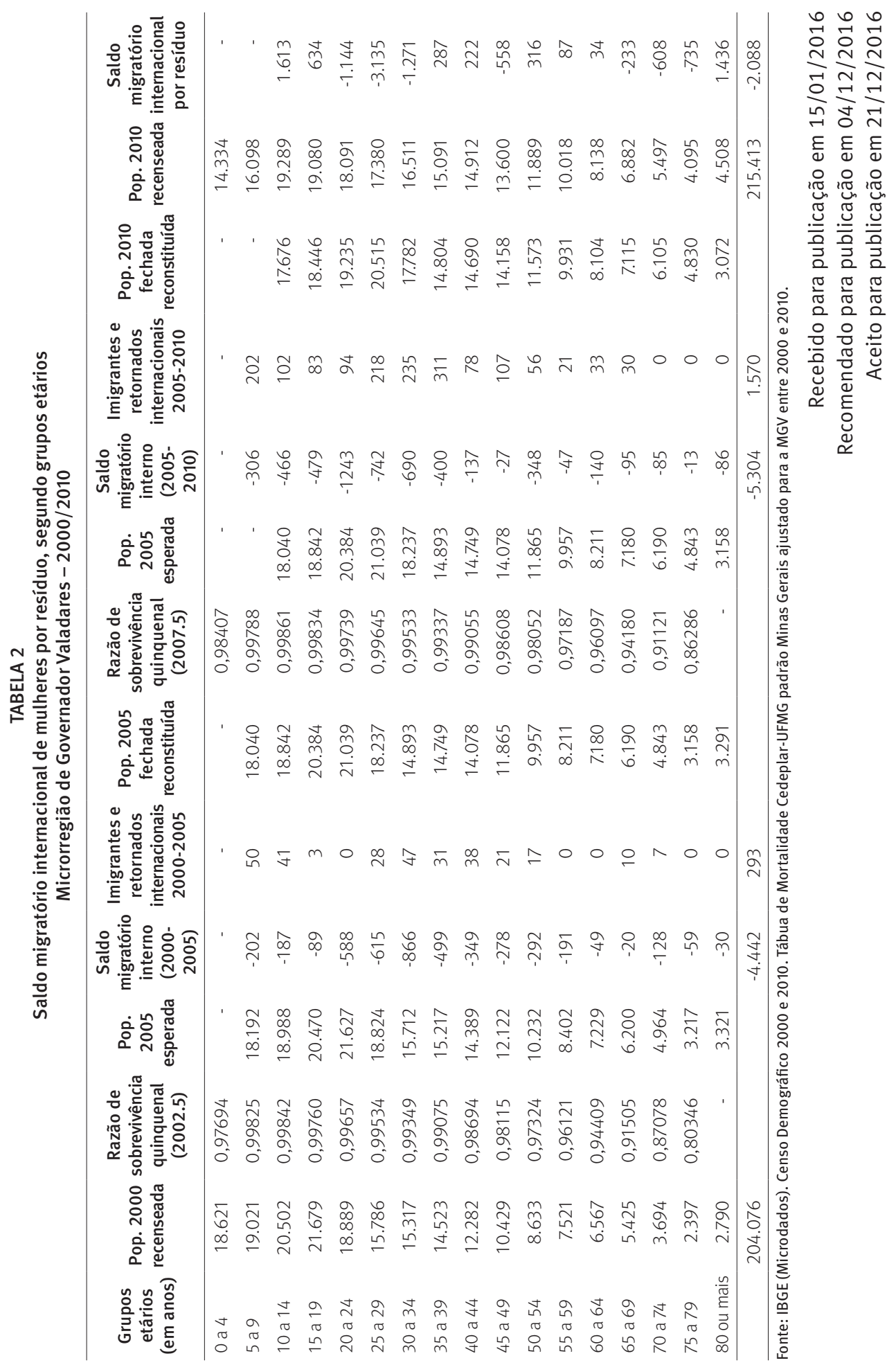

